А. А. Коваленко ${ }^{1}$ О. С. Ляшенко ${ }^{1}$ О. Ф. Даниленко ${ }^{2}$

${ }^{1}$ Харківський національний університет радіоелектроніки, Харків, Україна

${ }^{2}$ Національний технічний університет «Харківський політехнічний інститут», Харків, Україна

\title{
ПОВЕДІНКА ЧЕРГ ПІД ЧАС ВИКОРИСТАННЯ ІЄРАРХІЧНОЇ МОДЕЛІ
}

\begin{abstract}
Процеси, які мають довгострокові залежності, можуть породити набагато важчий хвіст у трафіковому процесі, ніж традиційний вхідний Пуассонівський процес. Мета статті - дослідження поведінки черг комп'ютерних мереж при використанні ієрархічної моделі на прикладі черги до сервера. Базова модель. Для дослідження поведінки одиничної черзі мультифрактального трафіку, згенерованого ієрархічною моделлю, розглянуто дворівневу ієрархічну модель, в якій процес відновлення проходить через періоди генерації трафіку і періоди, коли генерація трафіку відсутня. Кожен період генерації трафіку складається, в свою чергу, 3 кількох аналогічних періодів менших рівнів $\mathrm{i}$ періодів недоступності трафіку. Результати дослідження. Запропонована модель використана на вході черзі сервера для обчислення розподілу хвоста контентного процесу черзі, тобто промодельовані ON-OFF процеси генерації трафіка. За допомогою збудованої моделі проаналізований контентний процес при часі, який наближається до нескінченності. Його асимптотична поведінка моделюється на відліках, котрі отримані в контрольних точок відновлення. 3 використанням отриманих результатів доведено, що контент ний процес проявляє ступеневу залежність поведінки в часових контрольних точок відновлення. Виходячи з цього, за допомогою перетворення Лапласа отримані вирази для розрахунку розвитку у часі важкого хвоста трафікового процесу. Висновки. Розроблено підхід до визначення поведінки черг під час використання ієрархічної моделі. Напрям подальших досліджень - дослідити взаємодію процесів формування черг з важкими хвостами.
\end{abstract}

Кл юч ов і сл о в а : комп'ютерна мережа, затримка пакетів, трафік, важкий хвіст.

\section{Вступ}

Аналіз черг є надзвичайно важливим процесом при управлінні трафіком комп'ютерних та плануванні різноманітних мережевих політик. Аналіз існуючих робіт [1-6] показав, що процеси, які мають довгострокові залежності, можуть породити набагато важчий хвіст у трафіковому процесі, ніж традиційний вхідний Пуассонівський процес. У роботах [7-12] були запропоновані ієрархічні моделі комп'ютерних систем, але в них не був врахований непуасонівський характер поведінки черг. Крім того, слід відмітити, що питання дослідження поведінки черг у комп'ютерних мережах є доволі необхідним як при проектуванні, так і при розвитку різноманітних систем, котрі використовують інформаційні технології [13-29].

Мета статті - дослідження поведінки черг у комп'ютерних мережах при використанні ієрархічної моделі на прикладі черги до сервера.

\section{Результати досліджень}

1. Моделювання вхідного потоку. Для дослідження поведінки одиничної черзі мультифрактального трафіку, згенерованого ієрархічною моделлю, розглянемо дворівневу ієрархічну модель, в якій процес відновлення проходить через періоди генерації трафіку (ON) і періоди, коли генерація трафіку відсутня (OFF). Кожен період ON складається, в свою чергу, з кількох аналогічних періодів ON менших рівнів і періодів OFF. Така модель використовується на вході черзі сервера для обчислення розподілу хвоста C (t) контентного процесу черзі.

Для цього спочатку обчислимо контентний процес в кінцевих точках періодів OFF (контрольних точок відновлення періодичного процесу відновлення). Потім застосуємо теорему Кохена [11] для отримання асимптотичної поведінки контентного процесу при часі, який наближається до нескінченності. У підсумку, розширимо отримані результати для будь-якої точки часу і обчислимо асимптотичну поведінку контентного процесу при часі, який прагне до нескінченності.

2. Контентний процес в контрольних точок відновлення і його асимптотична поведінка. Для досягнення універсальності покладемо, що трафік генерується 3 одиничною інтенсивністю в періоді ON. Нехай послідовність відновлень $\left\{S_{n}, n \geq 0\right\}$ при

$$
S_{n}=S_{0}+\sum_{i=1}^{n}\left(B_{i}+I_{i}\right), n \geq 1, \text { conclusions }
$$

де $\left\{B_{i}, i \geq 1\right\}$ представляє періоди $\mathrm{ON}$, a $\left\{I_{i}, i \geq 1\right\}-$ періоди OFF. $S_{0}$ - випадкова величина, обрана таким чином, щоб зробити $S_{n}$ стаціонарним процесом і складається з ON періоду $B_{0}$ i OFF періоду $I_{0}$. Детальний розрахунок значення $S_{0}$ наведено в [6]. Кожен ON період $B_{i}$ далі може бути виражений як

$$
B_{i}=\sum_{j=1}^{N_{i}}\left(b_{i, j}+i_{i, j}\right)
$$

де $b_{i, j}$ и $i_{i, j}$ представляють $j$-й ON і OFF періоди в $B_{i}$, відповідно, а $N_{i}$ - число періодів ON найвищого рівня в $B_{i}$. Тоді $S_{n}$ може бути переписано як

$$
\sum_{i=0}^{n}\left(\sum_{j=1}^{N_{i}}\left(b_{i, j}+i_{i, j}\right)+I_{i}\right)
$$

Нехай $\left\{\gamma_{t}, t \geq 0\right\}$ буде процесом-індикатором, який дорівнює 1 в періоді ON і 0 в інших випадках. Кумулятивний мультифрактальний вхід, згенерований ієрархічною моделлю до моменту $t$, може бути виражений як

$$
a_{t} \stackrel{\Delta}{=} \int_{0}^{t} \gamma_{u} d u
$$


Покладемо $a_{t} \approx t \cdot N \cdot m_{O n} /\left(m_{O N}+m_{O F F}\right), \quad$ де $N=E\left(N_{i}\right), \quad m_{O N}=N\left(m_{o n}+m_{\text {off }}\right)$ і $N_{i} \in$ незалежними рівномірно розподіленими. Довготривала вхідна швидкість дорівнює $N m_{o n} /\left(m_{O N}+m_{O F F}\right)$. Покладемо, що швидкість обслуговування системи при сумарній кількості трафіку $x$ дорівнює

$$
r_{S}(x)=\left\{\begin{array}{l}
r, \text { если } x>0, \\
0, \text { если } x \leq 0,
\end{array}\right.
$$

і швидкість генерації трафіку не перевищує швидкість його обробки, тобто

$$
N m_{\text {on }} /\left(m_{\text {ON }}+m_{\text {OFF }}\right)<r<1,
$$

а контентний процес $\{C(t), t \geq 0\}$ задовольняє умові

$$
d C(t)=d a_{t}-r_{S}(C(t)) d t .
$$

Тобто, в періоді ON трафік входить в систему зі швидкістю $1-r$, а в періоді OFF трафік обслуговується зі швидкістю $r$. Можна показати, що процес $\{C(t), t \geq 0\}$ є регенеративним з часом регенерації

$$
\left\{D_{n}\right\} \stackrel{\Delta}{=}\left\{S_{n}: C\left(S_{n}-\right)=0\right\} .
$$

Необхідно зауважити, що часові точки регенерації є точками часу, коли контентний процес спустошується і вхідний процес починає заповнювати чергу. Оскільки $\left\{S_{n}\right\}$ - стабільний процес відновлення, то, відповідно до теореми Сміта [11], $\left\{C\left(S_{n}\right), n \geq 0\right\}$ i $\{C(t), t \geq 0\}$ мають обмежені розподіли. Для обчислення обмежених розподілів $\left\{C\left(S_{n}\right), n \geq 0\right\}$ i, $\{C(t), t \geq 0\}$ висловимо загальну тривалість періоду ON до $n$-ї рекурсії як

$$
S_{n}^{B}=\sum_{i=0}^{n} B_{i}=\sum_{i=0}^{n} \sum_{j=1}^{N_{i}}\left(b_{i, j}+i_{i, j}\right),
$$

а загальну тривалість періоду OFF до $n$-ї рекурсії як

$$
S_{n}^{I}=\sum_{i=1}^{n} I_{i} .
$$

Нехай $\Omega_{n} \stackrel{\Delta}{=}(1-r) \Omega_{n}^{b}-r \Omega_{n}^{i}, \quad \Omega_{n}^{b}=\sum_{i=0}^{n} \sum_{j=1}^{N_{i}} b_{i, j} \quad$ і $\Omega_{n}^{i}=\sum_{k=0}^{n} \sum_{j=1}^{N_{i}} i_{k, j}$. Оскільки $C(t)$ зростає зі швидкістю 1- $r$ під час періоду $\mathrm{ON}$, визначимо ознака порожнього моменту як

$$
T_{s}=\inf _{n}\left((1-r) \Omega_{n}^{b}-r_{s}\left(\Omega_{n}^{i}+S_{n}^{I}\right) \leq 0\right) .
$$

Якщо $T_{s}=t$, маємо:

$$
(1-r) \Omega_{j}^{b}-r_{s}\left(\Omega_{j}^{i}+S_{n}^{I}\right)\left\{\begin{array}{l}
>0, \text { если } 1 \leq j<t, \\
\leq 0, \text { если } j=t .
\end{array}\right.
$$

Нехай $1_{\text {cond }}$ буде індикатриса, тобто $1_{\text {cond }}=1$, якщо cond зберігається i $1_{\text {cond }}=0$ в інших випадках. Згідно теореми Сміта, для $x>0$, маємо вирази для розрахунку розвитку важкого хвоста трафікового процесу:

$$
\begin{gathered}
\bar{U}(x)=1-U(x) \stackrel{\Delta}{=} P_{r}\left(C\left(S_{n}\right)>x\right) \rightarrow \\
\rightarrow E\left(\sum_{j=1}^{T_{s}} 1_{C}\left(S_{j}\right)>x\right) / E\left(T_{s}\right) ; \\
\bar{V}(x)=1-V(x) \stackrel{\Delta}{=} P_{r}(C(t)>x) \rightarrow \\
\rightarrow E\left(\int_{j=1}^{D_{1}} 1_{C(u)>x} d u\right) / E\left(S_{T_{s}}\right),
\end{gathered}
$$

де $E\left(S_{T_{S}}\right)=\left(m_{O N}+m_{O F F}\right) E\left(T_{s}\right)$. Для обчислення $U(x)$ маємо таке ітеративне співвідношення:

$$
\begin{aligned}
C\left(S_{n+1}\right)= & \left(C\left(S_{n}\right)+\sum_{j=1}^{N_{n+1}}\left((1-r) b_{n+1, j}-r i_{n+1, j}\right)-\right. \\
& \left.-r I_{n+1}\right)^{+}=\left(C\left(S_{n}\right)+\eta_{n+1}\right)^{+},
\end{aligned}
$$

де $\left\{\eta_{n}=\sum_{j=1}^{N_{n}}\left((1-r) b_{n, j}-r i_{n, j}\right)-r I_{n}\right\}-$ послідовність незалежних змінних з матсподіванням

$$
\begin{aligned}
E\left(\eta_{n}\right) & =N(1-r) m_{\text {on }}-N r m_{\text {off }}-r m_{O F F}= \\
& =N m_{\text {on }}-r\left(m_{O N}+m_{O F F}\right) .
\end{aligned}
$$

Вираз $m_{O N}=N\left(m_{o n}+m_{\text {off }}\right)$ використовується в (15). Вираз (14) тепер може бути записано як $C\left(S_{n+1}\right)=\left(\left(\left(C\left(S_{0}\right)+\eta_{1}\right)^{+}+\eta_{2}\right)^{+}+\ldots+\eta_{n+1}\right)^{+}$, тобто вважаючи, що $C(0)=0$, отримаємо

$$
C\left(S_{n}\right) \sim \max _{0 \leq n<\infty} \sum_{i=1}^{n} \eta_{i}<\infty .
$$

3. Аналіз часових околів. Особливу увагу необхідно приділити околиці часових точок $\left\{S_{n}\right\}$. Так, можна зрушити разом все найвищі періоди оn в кожному з періодів ON. Нехай контентним процесом, відповідним змішаної вхідний моделі, буд $\tilde{C}\left(S_{n}\right)$. Доведемо лему.

Лема. Контентні процеси в момент часу $\left\{S_{n}, n \geq 0\right\}$ є однаковими для вихідної і змішаної вхідних моделей, тобто

$$
C\left(S_{n}\right)=\tilde{C}\left(S_{n}\right) .
$$

Доведення. Важливо довести, що перший цикл починається в $C(0)=\tilde{C}(0)=0$. При обох вхідних моделях, час циклу однаково, і може бути позначено як $T=T_{O N}+T_{O F F} \cdot T_{O N}$. може, в свою чергу, бути виражено як $T_{O N}=T_{o n}+T_{o f f}$, де $T_{o n}-$ сума всіх найвищих періодів on, а $T_{o f f}$ - сума всіх найвищих періодів off. Отже, $T=T_{\text {on }}+T_{\text {off }}+T_{O F F}$. Єдиним розходженням між цими моделями $\epsilon$ розташування найвищих періодів on і off. Маємо

$$
C\left(S_{1}\right)=1 \cdot T_{\text {on }}-r \cdot\left(T_{\text {off }}+T_{\text {OFF }}\right)=\tilde{C}\left(S_{1}\right),
$$

незалежно від розташування цих періодів on і off. 
Тепер можна описати $\bar{U}(x)$.

Теорема. 3 огляду на розподілу $P$ і $M$, а також

$$
\begin{gathered}
\bar{P}(x) \sim x^{\alpha_{b}} L(x), 1<\alpha_{b}<2, x \rightarrow \infty, \\
\bar{M}(x) \sim x^{\alpha_{N}} L(x), 1<\alpha_{N}<2, x \rightarrow \infty,
\end{gathered}
$$

маємо $\bar{U}(x) \sim \xi x^{-\left(\alpha_{\min }-1\right)} L(x), x \rightarrow \infty$,

$$
\xi=\frac{\rho}{1-\rho} \cdot \frac{(1-r)^{\alpha_{\min }-1}}{\left(\alpha_{\min }-1\right) N m_{o n}}, \rho=\frac{N m_{o n} \cdot(1-r)}{\left(N m_{o f f}+m_{O F F}\right) r}<1 \text {. }
$$

Доведення. Згідно лемі $C\left(S_{n}\right)=\tilde{C}\left(S_{n}\right)$, досить розглянути контентний процес $\left\{\tilde{C}\left(S_{n}\right), n \geq 0\right\}$ при змішаній вхідний моделі. Таким чином ми маємо новий $\mathrm{ON}^{\prime} / \mathrm{OFF}^{\prime}$ процес, де $\mathrm{ON}$ дорівнює сумі кількох найвищих періодів on, а OFF' - сумі OFF і декількох найвищих періодів off. Далі можна показати, що розподіл $\mathrm{ON},\left\{\tilde{C}\left(S_{n}\right), n \geq 0\right\}$, обумовлено правилом:

$$
1-F_{O N^{\prime}}(x) \sim x^{-\alpha_{\min }} L(x), x \rightarrow \infty,
$$

де $\alpha_{\min }=\min \left(\alpha_{b}, \alpha_{N}\right)$, а $L(x)$ - повільно змінюється функція. Для застосування теореми Кохена [12], наведемо нову ON '/ OFF' модель до GI / G / 1 моделі черги 3 щільністю трафіку

$$
\rho=N m_{\text {on }} \cdot(1-r) /\left(N m_{\text {off }}+m_{\text {OFF }}\right) r<1,
$$

і відповідний розподіл часу обслуговування в черзі GI / G / 1, $B(x)$, виглядає наступним чином:

$$
B(x) \sim F_{O N^{\prime}}((1-r) x) .
$$

Безпосередньо застосовуючи теорему Кохена, отримаємо

$$
\begin{aligned}
\bar{U}(x) & \sim \frac{\rho}{1-\rho} \cdot \frac{(1-r)^{\alpha_{\min }-1}}{\left(\alpha_{\min }-1\right) N m_{o n}} \cdot x^{-\left(\alpha_{\min }-1\right)} L(x), \\
\text { де } \alpha_{\min } & =\min \left(\alpha_{b}, \alpha_{N}\right) .
\end{aligned}
$$

Вираз (25) показує, що $C(t)$ проявляє ступеневу залежність поведінки в тимчасових контрольних точок відновлення. Виходячи 3 цього, обчислимо, оскільки $V(x)$ є більш загальним випадком ніж $U(x)$. Визначимо перетворення Лапласа для $V(x)$ i $U(x)$ як $V(s)$ і $U(s)$ відповідно.

Обчислення $\bar{V}(x)$. Для обчислення $\bar{V}(x)$, висловимо кількість часу, протягом якого процес $C(t)$ знаходиться за $x$ в $n$-му циклі ON/OFF як

$$
L_{n}(x)=\int_{S_{n}}^{S_{n+1}} 1_{(C(t)>x)} d t .
$$

Ми раніше визначили послідовності $\left\{B_{n}\right\}$, $\left\{I_{n}\right\}$ i $\left\{C\left(S_{n}\right)\right\}$. Далі визначимо послідовності $\left\{b_{n}^{m}\right\},\left\{i_{n}^{m}\right\}$ i $\left\{s_{n}^{m}\right\}$, для найвищих рівнів on, off i відновлюють послідовностей в періоді ON відповідно, і розглянемо відповідні стаціонарні послідовності $\left\{b_{n}^{m}\right\},\left\{i_{n}^{m}\right\}$ i $\left\{s_{n}^{m}\right\}$, і ретельним підбором розподілу на початку періоду [12].

\section{Висновки}

За допомогою збудованої моделі проаналізований контентний процес при часі, який наближається до нескінченності. Його асимптотична поведінка моделюється на відліках, котрі отримані в контрольних точок відновлення. Доведена теорема, котра дозволяє визначити асимптотичний характер динамічного процесу розвитку черги. 3 використанням отриманих результатів доведено, що контент ний процес проявляє ступеневу залежність поведінки в часових контрольних точок відновлення. Виходячи 3 цього, за допомогою перетворення Лапласа отримані вирази для розрахунку розвитку у часі важкого хвоста трафікового процесу. Отже, розроблено підхід до визначення поведінки черг під час використання ієрархічної моделі. Напрям подалыших досліджень - дослідити взаємодію процесів формування черг з важкими хвостами.

\section{СПИСОК ЛІТЕРАТУРИ}

1. Кучук Г.А. Метод оценки характеристик АТМ-трафика / Г.А. Кучук // Інформаційно-керуючі системи на залізничному транспорті, - 2003. - № 6. - С. 44-48.

2. Кучук Г. А., Можаєв О. О., Воробйов О. В. Метод агрегування фрактального трафіка. Радіоелектронні та комп'ютерні системи. 2006. № 6 (18). С. 181-188.

3. Saravana, Balaji B,, Karthikeyan, N.K. and Raj Kumar, R.S., (2018), "Fuzzy service conceptual ontology system for cloud service recommendation”, Computers \& Electrical Engineering, Vol. 69, pp. 435-446.

4. Saravana, Balaji B., Mohamed, Uvaze Ahamed, Eswaran C. and Kannan R., (2019), "Prediction-based Lossless Image Compression", Lecture Notes in Computational Vision and Biomechanics (Springer), Vol. 30, No 1, pp.1749 - 17961, DOI: https://doi.org/10.1007/978-3-030-00665-5 161

5. Кучук Г. А. Фрактальный гауссовский шум в трафиковых трассах / Г.А. Кучук // Системи обробки інформації. 2004. - № 3(31). - С. 91-100.

6. Кучук Г.А. Аналіз та моделі самоподібного трафіка / Г.А. Кучук, О.О. О.В. Можаев, Воробйов // Авиационнокосмическая техника и технология. - 2006. - Вып. 9 (35). - С. 173-180.

7. Amin Salih M., Potrus M.Y._A Method for Compensation of TCP Throughput Degrading During Movement Of Mobile Node. ZANCO Journal of Pure and Applied Sciences. 2015. Vol. 27, No 6. P. 59-68.

8. Gomathi, B, Karthikeyan, N.K. and Saravana, Balaji B., (2018), "Epsilon-Fuzzy Dominance Sort Based Composite Discrete Artificial Bee Colony optimization for Multi-Objective Cloud Task Scheduling Problem", International Journal of Business Intelligence and Data Mining, Vol. 13, Issue 1-3, pp. 247-266, DOI: https://doi.org/10.1504/IJBIDM.2018.088435

9. Dhivakar B., Saravanan S.V., Sivaram M., Krishnan R.A. Statistical Score Calculation of Information Retrieval Systems using Data Fusion Technique". Computer Science and Engineering. 2012. Vol. 2, Issue 5. pp.43-45. doi: http://doi.org/10.5923/j.computer.20120205.01 
10. Sivaram, M., Batri, K., Amin Salih, Mohammed and Porkodi V. (2019), "Exploiting the Local Optima in Genetic Algorithm using Tabu Search", Indian Journal of Science and Technology, Volume 12, Issue 1, doi: http://doi.org/10.17485/ijst/2019/v12i1/139577

11. Kuchuk G., Nechausov S., Kharchenko, V. Two-stage optimization of resource allocation for hybrid cloud data store. International Conference on Information and Digital Technologies. 2015. P. 266-271.

12. Ruban, I. Redistribution of base stations load in mobile communication networks / I. Ruban, H. Kuchuk, A. Kovalenko // Innovative technologies and scientific solutions for industries. - 2017. - No 1 (1) - P. 75-81.

13. Коваленко А.А. Сучасний стан та тенденції розвитку комп'ютерних систем об'єктів критичного застосування / А.А. Коваленко, Г.А. Кучук // Системи управління, навігації та зв’язку. - Полтава . ПНТУ, 2018. - Вип. 1(47). - С. 110113. DOI : https://doi.org/10.26906/SUNZ.2018.1.110

14. Кучук Г. А. Модель процесса эволюции топологической структуры компьютерной сети системы управления объектом критического применения / Г.А. Кучук, А.А. Коваленко, А.А. Янковский // Системи обробки інформації. - 2014. - № 7(123). - С. 93-96.

15. Кучук Г. А. Метод параметрического управления передачей данных для модификации транспортных протоколов беспроводных сетей / Г.А. Кучук, А.С. Мохаммад, А.А. Коваленко // Системи обробки інформації. - 2011. - № 8(98). - C. 211-218.

16. Кучук Г.А. Метод мінімізації середньої затримки пакетів у віртуальних з'єднаннях мережі підтримки хмарного сервісу / Г.А. Кучук, А.А. Коваленко, Н.В. ЛуковаЧуйко // Системи управління, навігації та зв'язку. - Полтава . ПНТУ, 2017. - Вип. 2(42). - С. 117-120.

17. Sivaram, M., Yuvaraj, D., Amin Salih, Mohammed, Porkodi, V. and Manikandan V. (2018), "The Real Problem Through a Selection Making an Algorithm that Minimizes the Computational Complexity", International Journal of Engineering and Advanced Technology, Vol. 8, iss. 2, 2018, pp. 95-100.

18. Sivaram, M., Porkodi, V., Mohammed, A.S., Manikandan V. Detection of Accurate Facial Detection Using Hybrid Deep Convolutional Recurrent Neural Network. ICTACT Journal on Soft Computing. 2019. Vol. 09, Issue 02. pp. 1844-1850.

19. Mohammed, A. S. Optimal Forecast Model for Erbil Traffic Road Data. ZANCO Journal of Pure and Applied Sciences. 2017. Vol. 29, No 5. P. 137-145. DOI: https://doi.org/10.21271/ZJPAS.29.5.15

20. Amin Salih M., Yuvaraj D., Sivaram M., Porkodi V. Detection And Removal Of Black Hole Attack In Mobile Ad Hoc Networks Using Grp Protocol. International Journal of Advanced Research in Computer Science. Vol. 9, No 6. P. 1-6, DOI: http://dx.doi.org/10.26483/ijarcs.v9i6.6335

Рецензент: д-р техн. наук, проф. І. В. Рубан, Харківський національний університет радіоелектроніки, м. Харків Received (Надійшла) 09.01.2019 Accepted for publication (Прийнята до друку) 20.02.2019

\title{
Поведение очередей при использовании иерархической модели
}

\author{
А. А. Коваленко, А. С. Ляшенко, А. Ф. Даниленко
}

Процессы, которые имеют долгосрочные зависимости, могут породить гораздо тяжелее хвост в трафикового процессе, чем традиционный входной пуассоновский процесс. Цель статьи - исследование поведения очередей компьютерных сетей при использовании иерархической модели на примере очереди к серверу. Базовая модель. Для исследования поведения единичной очереди мультифрактального трафика, сгенерированного иерархической моделью, рассмотрены двухуровневую иерархическую модель, в которой процесс восстановления проходит через периоды генерации трафика и периоды, когда генерация трафика отсутствует. Каждый период генерации трафика состоит, в свою очередь, из нескольких аналогичных периодов меньших уровней и периодов недоступности трафика. Результаты исследования. Предложенная модель использована на входе очереди сервера для вычисления распределения хвоста контентного процесса очереди, то есть промоделированы on-off процессы генерации трафика. С помощью построенной модели проанализирован контентный процесс по времени. Его асимптотическое поведение моделируется по отсчетам, которые получены в контрольных точек восстановления. С использованием полученных результатов доказано, что контентный процесс проявляет степенную зависимость поведения во временных точек восстановления. Исходя из этого, с помощью преобразования лапласа полученные выражения для расчета развития во времени тяжелого хвоста трафикового процесса. Выводы. Разработан подход к определению поведения очередей при использовании иерархической модели. Направление дальнейших исследований - исследовать взаимодействие процессов формирования очередей с тяжелыми хвостами.

Ключевы е слов а : компьютерная сеть, задержка пакетов, трафик, тяжелый хвост.

\section{Queue behavior when using a hierarchical model}

\section{A. Kovalenko, O. Lyashenko, O. Danilenko}

Processes that have long-term dependencies can generate a much heavier tail in the traffic process than the traditional input Poisson process. The purpose of the article is to study the behavior of computer network queues when using a hierarchical model using the example of a queue to a server. The based model. To study the behavior of a single queue of multifractal traffic generated by a hierarchical model, we consider a two-level hierarchical model in which the recovery process passes through traffic generation periods and periods when traffic generation is absent. Each period of traffic generation consists, in turn, of several similar periods of lower levels and periods of unavailability of traffic. The results of the study. The proposed model is used at the input of the server queue to calculate the distribution of the tail of the queue content process, that is, the traffic generation processes are modeled on-off. Its asymptotic behavior is modeled on samples that are obtained at control restore points. Using the obtained results, it was proved that the content process manifests a power dependence of behavior at the time points of recovery. On this basis, using the Laplace transformation, the obtained expressions for calculating the development in time of the heavy tail of the traffic process. Conclusions. An approach to determining the behavior of queues using the hierarchical model has been developed. The direction of further research is to investigate the interaction of the processes of formation of queues with heavy tails.

Keywords : computer network, packet delay, traffic, heavy tail. 